\title{
'Every medicine is part poison': a qualitative inquiry into the perceptions and experiences of choosing contraceptive methods of migrant Chinese women living in Australia
}

\author{
Hankiz Dolan ${ }^{1,2^{*}} \mathbb{D}$, Mu Li $^{1}$, Deborah Bateson ${ }^{3,4}$, Rachel Thompson ${ }^{1,2}$, Chun Wah Michael Tam ${ }^{5,6}$, \\ Carissa Bonner ${ }^{1,2}$ and Lyndal Trevena ${ }^{1,2}$
}

\begin{abstract}
Background: In Australia, ethnic Chinese people are one of the largest, youngest and fastest growing overseas-born groups. Yet, little is known about their perceptions of contraceptive methods and their experiences with choosing one. Decisions about contraceptive methods are preference sensitive. Understanding the influencing factors of Chinese migrant women's contraceptive method choice and practices will help cater to their decision-making needs in a culturally sensitive and responsive way.
\end{abstract}

Methods: A qualitative study design underpinned by critical realism approach was used to explore Chinese migrant women's perceptions and experiences of choosing contraceptive methods. Semi-structured interviews were conducted with 22 women who self-identified as being ethnically Chinese and had been living in Australia for no more than 10 years. The interview guide was adapted from the Ottawa Decision Support Framework. Majority of the interviews were conducted in Mandarin Chinese. Transcribed data was analysed using thematic analysis method.

Results: Four major themes were identified, including: 'every medicine is part poison: hormonal contraceptives cause harm to the body'; 'intrauterine device, a device used in the past for married women'; 'it takes two (or one) to decide, depending on the relationship dynamics and contraception preferences'; and 'it is not necessary to seek medical advice in choosing contraceptive methods'.

Conclusions: Our findings suggest that Chinese migrant women's perceptions and experiences of choosing contraceptive methods are influenced by complex personal, cultural, societal and inter-relational factors. Chinese migrant women were cautious of using hormonal methods due to fears of side-effects, including reduced or absent menstrual bleeding. Women were also reluctant to consider intrauterine devices as options due to associating them with past experiences of other women and themselves and also fears of potential complications. There was a reluctant attitude towards seeking medical advice regarding contraception due to beliefs that needing to use contraception is not an illness requiring treatment. Such findings are likely to be useful in increasing healthcare professionals' and policy makers'understanding of Chinese migrant women's contraceptive method preferences, beliefs and behaviours. They also

\footnotetext{
*Correspondence: hekp5025@uni.sydney.edu.au

1 School of Public Health, The University of Sydney, Room 125, Edward

Ford Building, Sydney, NSW 2006, Australia

Full list of author information is available at the end of the article
}

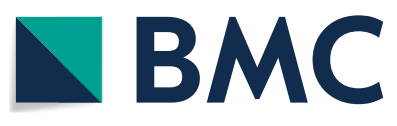

(c) The Author(s) 2021. Open Access This article is licensed under a Creative Commons Attribution 4.0 International License, which permits use, sharing, adaptation, distribution and reproduction in any medium or format, as long as you give appropriate credit to the original author(s) and the source, provide a link to the Creative Commons licence, and indicate if changes were made. The images or other third party material in this article are included in the article's Creative Commons licence, unless indicated otherwise in a credit line to the material. If material is not included in the article's Creative Commons licence and your intended use is not permitted by statutory regulation or exceeds the permitted use, you will need to obtain permission directly from the copyright holder. To view a copy of this licence, visit http://creativecommons.org/licenses/by/4.0/. The Creative Commons Public Domain Dedication waiver (http://creativeco mmons.org/publicdomain/zero/1.0/) applies to the data made available in this article, unless otherwise stated in a credit line to the data. 
help to develop culturally and linguistically sensitive strategies, which goes beyond the provision of contraceptive counselling, in assisting Chinese migrant women's decision-making needs.

Keywords: Contraception, Chinese migrant women, Decision-making, Critical realism

\section{Background}

Australia is a multicultural country. Approximately one in four people who reside in Australia are born overseas[1]. In 2016, 5.6\% of Australia's total population identified themselves as having Chinese ancestry, while $2.2 \%$ identified as being born in China $[1,2]$. Among the Australian population who were born in China, 62.3\% held foreign nationality [3]. University students, including international students, accounted for $22 \%$ of the total China-born population [4]. The median age for people who were born in China was 33 in 2016 [3], making them one of the youngest, largest and fastest growing overseasborn groups in Australia.

Contraception is a key component of sexual and reproductive health [5]. The fundamental purpose of contraception is to prevent unintended pregnancies and increase people's control over whether or not, and when to have children and how many to have [6]. In Australia, there are many types of contraceptive methods, including intrauterine devices (IUDs), implant, oral contraceptive pills, vaginal ring, condoms, diaphragm and male and female sterilisation, are available for people to choose from [7]. Among those methods, contraceptive pills are the most commonly used by women in Australia, followed by condoms and sterilisation [8]. Compared to Australian-born women, women from non-Englishspeaking backgrounds who were born overseas are less likely to report use of any contraceptive method [9]. They may face barriers in accessing evidence-based, culturally and linguistically sensitive health information, and are more likely to rely on family, friends or media for contraceptive information which may not be based on accurate medical evidence [10-12]. Apart from cultural and language barriers, misconceptions or concerns about contraception such as weight gain, bleeding, cancer risk and worries about side-effects were also reported by migrant and refugee women [12].

It has also been reported that international students, including those from China, have low sexual health literacy and limited knowledge about contraceptive methods [13-15]. They are reported to be reluctant to speak to healthcare providers about sexual and reproductive health matters due to fears of embarrassment and being unaware of healthcare providers' potential role in providing sexual and reproductive health counselling and related services [13-15]. Little is known about Chinese migrant women's, including Chinese international students', perceptions and awareness of contraceptive methods and factors that influence their choice of contraceptives. Decisions about contraceptive methods are preference-sensitive [16]. Understanding the influencing factors of migrant Chinese women's contraceptive method choice and practices will help cater to their decision-making needs in a culturally sensitive and responsive way. Therefore, we set out to explore Chinese women's knowledge, perceptions and views of contraceptive methods, and their experiences with choosing one in Australia using a qualitative critical realist approach.

\section{Method}

\section{Research team and reflexivity}

The research team comprised of members with a wide range of expertise in areas such as general practice, sexual and reproductive health, maternal and child health, psychology and behaviour change. The study was conducted as part of the lead author's (HD) doctorate project. HD is a female and is a medical graduate. She is fluent in English and Mandarin Chinese. She and all other team members had training in qualitative research prior to conducting the study. None of the team members had any personal or professional relationships or contact with the participants prior to the recruitment.

\section{Study design}

This qualitative research was informed by the critical realism theoretical approach. Critical realism is based on the ontological assumption that reality consists of three layers: 'empirical' reality which is observed, experienced or perceived by humans; 'actual' reality of events which occur regardless of human knowledge; and 'real' reality of causal mechanisms such as social and cultural structures which shape the manifestation of empirical reality [17]. In the context of contraceptive method choice, the 'empirical' level concerns with beliefs, perceptions and experiences of women with the specific contraceptive methods. At the 'actual' level is the attributes, risks and benefits of contraceptive methods, which may or may not be known to the women. The 'real' reality level is the structural generative mechanisms and factors that cause women to come to perceive or experience contraceptive methods in certain ways. The critical realist approach goes beyond describing social phenomena and seeks to elaborate on fundamental underlying causes of such observed, experienced and perceived empirical 
reality [18]. We took a critical realism approach because we believed that women's perceptions of contraceptive methods and their experiences of choosing one are manifestations of the interplay of social, cultural and individual contexts or mechanisms.

Given the potentially sensitive and personal nature of this topic, we chose semi-structured individual interviews for data collection. Semi-structured interviews are usually guided by pre-defined questions [19]. However, they also have the advantage of allowing the researcher to tailor the questions to each participant in order to ensure the natural flow of the conversation [19].

\section{Recruitment}

We recruited women who self-identified as ethnically Chinese, aged between 18 and 45 years and had been living in Australia for no more than 10 years. We used a purposive sampling method to cover a diverse range of participant characteristics, including age (e.g., 18-30 years versus 30-44 years), Australian residency status (citizen, permanent resident versus temporary residents) and relationship status (married, living with a partner versus not-married, not-living with a partner). We utilised several recruitment methods. First, we placed Chinese and English versions of flyers and posters at our recruitment sites, including a university campus, university health clinic, family planning clinics and a Chinese community service centre. Second, we posted similar information on one of the largest Chinese Australian social networking sites, Oursteps. Third, HD approached potential participants directly in the waiting room of one of the non-profit family planning clinics in Sydney. Given the popularity of WeChat, a social media and messaging app, among people from Chinese background living in Australia, we registered a WeChat account on a studyspecific mobile phone device and specified our WeChat details and QR code on our recruitment materials. When women contacted the research team expressing their interest in the study, we sent them plain-language 'participant information statement' and consent form in either Chinese or English language, depending on their preferences. Interviews were scheduled at a time convenient to the participants.

\section{Data collection}

Interviews were conducted between July 2018 and January 2019. HD conducted all interviews with the participants at mutually agreed safe and private venues in metropolitan Sydney. Interviews were completed via telephone if preferred. Participants were given a choice to be interviewed either in Mandarin Chinese or English. Each interview was divided into two parts. In the first part, we we conducted the interview using a topic guide that was primarily adapted from the Ottawa Decision Support Framework [20], which included questions relating to contraception attitude, knowledge, perceptions, experiences, decisional conflict and support needs. The interview topic guide is provided as Additional file 1. We modified interview questions iteratively throughout the data collection. In the second part, women were shown a 8-page English and Chinese-translated contraceptive methods decision aid and probed to provide feedback. Only the data from the first part was analysed and reported for this paper. Participants each received a 30AUD shopping voucher for their participation.

All interviews except one were audio-recorded with the consent from the participants. One participant did not consent to be audio-recorded, and detailed field notes were collected instead. HD transcribed the recordings verbatim, and this process formed the early stages of the data analysis. We chose to transcribe the interview audio-recordings in the original language (i.e., either Chinese or English) to avoid loss of meaning due to translation [21]. Only one transcript was entirely in English. HD translated two additional Chinese transcripts into English for the view of other non-Chinese speaking team members. HD also translated the initial thematic table, which organises participant quotes under each potential candidate themes, for team discussion. Translation of key terms and concepts were discussed with the second author $(\mathrm{ML})$ who is a native Chinese speaker.

\section{Data analysis}

We followed the thematic analysis method [22] within a critical realism approach to analyse the data. As the first step of the analysis, HD transcribed and read all the transcripts while other team members read selected transcripts to familiarise themselves with the data. HD coded all transcripts using NVivo 12 [23] primarily in English. Some key codes were accompanied by source Chinese words and phrases. Other team members coded selected transcripts. Our initial codes were mainly driven by raw data inductively. HD wrote memos after coding each transcript to record data impression and analytical thinking. We held regular team meetings where we employed a peer debriefing strategy to review the data and analysis process, discuss the differential interpretation of the data and appraise the conceptualisation of research findings $[24,25]$. We collapsed, clustered and organised the initial codes in a recursive manner to identify recurring patterns and candidate themes. We used thematic table and diagram to identify themes that were internally homogenous and externally heterogeneous. During theme development and preparation of final analysis report, we engaged with existing literature and theories (abduction)[26] and/or contextual and historical factors to move 
beyond the surface descriptions to seek explanations for key concepts, phenomena and causal mechanisms reflected throughout each theme (retroduction)[26]. As with critical realist epistemology, we took the stance that our explorations of such mechanisms are our attempts to approximate the 'truth' rather than to determine the 'truth' [26].

\section{Trustworthiness}

We established trustworthiness and rigor during data analysis by: engaging with the data for a prolonged period of time; keeping reflective memos during data collection and analysis; frequent debriefing with team members; using thematic tables and diagrams to establish analytical reasoning; and providing thick description of the study methodology and the data.

\section{Ethical consideraion}

We obtained ethics approval from the University of Sydney human research ethics committee [ref: 2018/159] and Family Planning New South Wales Project Ethical Risk Team [ref: PERT 25]. All participants read the participant information statement and consented to participate. Participation was voluntary and participants were informed that they can terminate the interviews anytime if they did not wish to continue.

\section{Results}

A total of 22 women who were living in Sydney metropolitan area took part in the interviews (Table 1). We conducted 16 face-to-face interviews and six phone interviews. Interviews lasted between 25 and $75 \mathrm{~min}$. We identified four overarching themes, each with two to three subthemes (Fig. 1).

\section{Theme one: 'Every medicine is part poison': hormonal contraceptives cause harm to the body}

The Chinese proverb 'every medicine is part poison' (是 药三分毒 Shì yào sān fēn dú) was repeatedly referred to by women expressing their beliefs and attitudes towards hormonal contraceptives, including oral contraceptive pills, hormonal IUDs, and progestogen-only implant. Most women were cautious of hormonal contraceptives because they believed that such medicines would disrupt their 'inner balance' and cause harm to their body. Such perceived harms included reduced or irregular menstrual bleeding, weight gain, acne and mood change. For many of our participants, it was implied that the benefits of avoiding irregular menstrual bleeding and internal imbalance outweighed the benefits of using hormonal
Table 1 Participant characteristics

\begin{tabular}{ll}
\hline & Number \\
\hline Age group & 13 \\
$18-30$ & 9 \\
$30-45$ & \\
Australian residency status & 9 \\
Australian citizen or permanent resident & 13 \\
Not an Australian citizen or permanent resident & \\
Relationship status & 10 \\
Married & 12 \\
Not married/not living with a partner & \\
Place of birth & 20 \\
Mainland China & 2 \\
Hong Kong, China & \\
Employment status & 9 \\
Employed & 10 \\
Student & 3 \\
Un-employed & \\
Number of children & 15 \\
None &
\end{tabular}

contraceptives, (i.e., to prevent pregnancy), especially when there were other 'safer' options available.

I always feel that every medicine is part poison, that is why I feel they [contraceptive pills] might, if you take them for long term, might have some impact on some body organs... I believe that and I just have that sort of fear, I just oppose taking pills (Participant 4, married, aged 30-45, one child)

Sub-theme 1a: Hormonal contraceptives disrupt normal menstrual bleeding patterns and inner hormonal balance One of the most frequently mentioned negative impacts of the hormonal contraceptives was reduced or irregular menstrual bleeding. Some women perceived this to be just one amongst several disadvantages of the hormonal contraceptives. Others had deliberately discontinued hormonal methods after a short period time of 'giving it a try' and experiencing this particular negative impact. When probed about the reasons for avoiding side-effects related to reduced or absent menstrual bleeding, women cited several personal beliefs. For some women, having monthly periods was seen as a sign of female fertility and womanhood. Reduced or absent menstrual bleeding were also perceived as signals of menopause, which would accelerate the female aging process. As one woman quoted: 


Theme
Every medicine is part poison: hormonal
contraceptives cause harm to the body
IUD, a device used in the past for
married women

\section{It takes two (or one) to decide, depending on the relationship dynamic and contraception preferences}

\section{It is not necessary to seek medical advice in choosing contraceptive methods}

\section{Subtheme}

Hormonal contraceptives disrupt normal menstrual bleeding patterns and inner hormonal balance

Condoms do no harm: choice by default

Past experiences of others and self

Placing physical object inside the body causes damage and injury

Husband using condom is an act of caring

Young women should be responsible for taking care of their body

Did not need to consult a doctor regarding contraceptive methods

Needing to use contraception is not an illness to be treated

Can get contraception related information elsewhere: reliance on Chinese language websites, social networking forums and WeChat groups

Fig. 1 Overview of themes and subthemes

As a Chinese woman, having monthly menstrual bleeding cycle is a sign of your fertility. If you suddenly don't have any periods, wouldn't it feel like you are having menopause... if I tell my mother that I stopped having periods after taking the pill, she would think that I am having menopause and I can't have any child in the future...she would have that sort of concerns and she would say, you have lost an important feature of womanhood

(Participant 19, married, aged 18-30, no children)

Others saw that having reduced, absent or irregular bleeding was a sign of underlying health problems. For example, one woman noted that she had an irregular menstrual cycle even without taking the contraceptive pills and believed the irregularity was related to her 'body constitution'. Another woman was strongly against taking oral contraceptive pills because she felt they 'harm the female body to a great degree. However, she had favourable attitudes towards the use of Chinese medicine in regulating menstruation. As she described:

[having period] is supposed to be a normal physiological thing... if suddenly there is no period, it feels very scary, and you would want to find out the rea- sons why, first you might go and do a pregnancy test to see if you are pregnant or not, if not pregnant, you would look for other reasons, just like my friend, if her period does not come or the amount is very little, she would buy medicines to help regulate her periods, we Chinese people all like taking Chinese medicines and things like that'

(Participant 10, not married, aged 18-30, no children)

Sub-theme 1b: Condoms do no harm: choice by default The use of male condoms was favoured by many of the participants, regardless of their marital status or whether or not they had given birth before. It was often described as a method which was convenient, easy to use, clean and efficient. Most importantly, for many participants, the male condom is a barrier method that stayed outside one's body and therefore it does not inflict 'harm' to the female body like the hormonal contraceptives do.

I don't like taking pills and things like that, because I always feel that things [medicine] you ingest would always cause some sort of harm to you, therefore, I am not very willing to take pills, I usually just use 
condoms...because you ingest things [as in take pills], I mean, if you could replace a method which requires you to ingest, then I think condoms are better, at least they stay outside

(Participant 14, not married, aged 18-30, no children)

Apart from the use of condoms, use of the 'safe period' method was also frequently mentioned by the participants. The common term they used to describe the safe period method was 'before seven after eight', which refers to a variation of calender method where 7 days before and 8 days after the first day of menstruation are considered safe to have unprotected sex. As one participant described:

My period is usually ok, relatively regular, but I would always count from the day when my period arrived, because my period is for 6 days, I count from that [first] day, then I add another 8 days and then I start using condoms

(Participant 8, married, aged 30-45, one child)

A few participants mentioned how they use a combination of condoms, safe period and withdrawal methods. Overall, the majority of participants preferred the use of condoms, sometimes in combination with 'natural' methods such as withdrawal or safe period method. For them, such combination not only delivered the benefit of avoiding pregnancy, but also safeguarded against 'sufferings' caused by using hormonal methods.

In China, withdrawal method is relatively popular, in fact, I know that the withdrawal method, it is not that effective, but, it may not sound very scientific, but for me, I rarely have periods, so, the chance of me falling pregnant is not big, and I only have one sex partner, two of us, then, first, we choose a safe time, second, he withdraws, in fact, with using condoms, it is 1:1 ratio

(Participant 2, not married, aged 18-30, no children)

\section{Theme two: The IUD, a device used in the past for married women}

This theme mainly captured women's perceptions around non-hormonal IUDs. It is important to note that many participants did not differentiate between the two types IUDs (hormonal versus non-hormonal) and they used the term 'ring' to describe all intrauterine contraceptive methods. IUDs are commonly known as 'contraceptive rings' in China because the earliest intrauterine devices that were widely used during the initial periods of the nationwide one-child policy were largely 'home-made' stainless-steel rings (SSR) [27]. SSRs were designed not to be removed after a first delivery [27]. It was in 1993 that China ceased manufacturing SSRs [27, 28]. To ensure the term 'ring' was not misinterpreted as referring to the hormonal vaginal ring currently available in Australia, we replaced the literal translation of 'ring' with 'IUD'.

\section{Sub-theme 2a: Past experiences of others and self}

When speaking of their knowledge and perceptions of IUDs, many women referred to the experiences of their mothers, female relatives or acquaintances of having IUDs. Some participants expressed their impression of the IUD being a contraceptive method of the past when married women were mandated to have them to prevent having further children. They expressed their impression and perceptions of the IUD being a device that causes pain and harm to the female body. In the accounts of those women, there was a general sense of rejection of IUDs as a sensible contraceptive option for them. It was implied that IUDs do not apply to their current situations where they are not constrained by family planning policies or they are not married or had children yet.

Honestly, I don't know how this thing work, I feel like in the old days, in China, if they did not allow you to have children anymore, some people in the villages would have this thing, but it must be quite painful. If you think about it, you put a thing inside [your body], just stretching it in causes pain, just thinking about it I don't think it is a good thing

(Participant 3, married, aged 30-45, one child)

We also had women in our study who had experienced IUD insertions as a routine postpartum procedure in the past. All those women described having unpleasant experiences with the IUDs, mainly due to side-effects, and removed their IUDs a short time after. Apart from citing their own experiences with IUDs, some participants also noted the dangers of IUDs, such as complications (even death) due to difficulties in removal, based on the experiences of their family or friends. Still, the IUD was described as if it was a thing of a 'past time' and 'past place'.

\section{Sub-theme 2b: Placing physical objects inside the body causes damage and injury}

Some women, without referring to past experiences of other women or what they heard or read about the historical use of IUDs for married women, expressed fears of placing a foreign object inside the female body. They expressed that doing so may cause pain and damage, and even the thought of putting something inside their body make them uncomfortable. The common reasons given 
for this were that they felt the IUD might penetrate the uterus wall, cause inflammation, bleeding or might fall out. Some women were fearful of the procedure of inserting the IUD, regarding it as a surgical procedure which was unwarranted.

because for me, I never had any surgical operation done, basically never had a big injury or went under the knife, just like that. That's why I feel that, if you want to put something inside your uterus, you must need to stretch it in or something like that, I just feel like I can't accept that, especially when it is just for birth control and you don't have any other illness that requires you to do so. That's why I would not

(Participant 14, not married, 18-30, no children)

\section{Theme three: It takes two (or one) to decide, depending} on the relationship dynamic and contraceptive preferences This theme captures an important aspect of contraceptive method-use decision-making, which is the decisionmaking within the dyadic partner relationship. We found that married and unmarried women varied in their opinions of their partners' involvement in choosing methods. Even within married couples, we found varied attitudes towards their husbands' involvement, depending on the current method of choice.

\section{Sub-theme 3a: A husband using a condom is an act of caring}

Some of our participants spoke of how their caring, understanding and responsible partners/husbands had enabled them to avoid using female-initiated hormonal contraceptive methods, such as pills or IUDs. There was a sense of acknowledgement and appreciation of their partners'/husbands' willingness to use condoms. As one woman described:

My partner is also very supportive of this decision to use condoms, and then, he does not ask for much, like he does not ask me to take pills things like that. Since he can live up to using condoms every time [when we have sex], to me, it is a very good thing and it makes me very happy. That's why we always use condoms

(Participant 19, married, aged 18-30, no children)

Another woman also spoke highly of her husband who was very cooperative and always wore a condom or withdrew on time, despite the fact that the majority of men dislike the feeling of a layer of plastic during sex or withdrawing just before reaching orgasm.

that is why I think highly of my husband, he is very considerate towards me, and that is why we can do this, it is not easy at all for a man

(Participant 22, married, 30-45, one child)

In contrast, some other women expressed a sense of frustration and/or distrust towards their husbands' willingness or consistent/correct use of condoms. One woman cited how her husband does not like the feeling of the condom and insists on using the withdrawal method, which makes her very worried. Another woman, while acknowledging that condom is an effective method which they are currently using, mentioned that her husband sometimes is not willing to wear one during sex.

One woman (married, aged 30-45, one child) who underwent termination of an unintended pregnany and had IUD inserted described how she felt 'in control' by not having to rely on her husband using the condom. She noted she did not involve her husband in choosing a female-initiated contraceptive method process, because she believed that 'things like this, women should make their own decisions'. As she put it:

with IUDs, I am the one who is taking control, after having the IUD I feel this way, see, with condoms, in fact the control power is with the other half, see, am I right, you can't do much if they don't use condoms (Participant 4, married, 30-45, one child)

The above woman was one of three married women in this study who were currently using IUDs as their contraceptive methods. A second woman, who had three children, did not involve her husband in choosing a female-initiated contraceptive method as well because, as she put it, 'not many men do a serious research on this matter.' The accounts of these two women capture a sense of frustration that, unlike themselves, their husbands do not take contraception 'seriously'.

\section{Sub-theme 3b: Young women should be responsible for taking care of their body}

The decision-making dynamic took a slightly different perspective for our participants who were unmarried and not living together with a partner. Majority of those unmarried women also preferred the use of condoms by their partners, mainly because they are not having sexual intercourse frequently. Therefore, for them, it was not worthwhile to take pills and suffer from side-effects. However, the decision to use condoms was primarily insisted upon by the women themselves, with their partners being expected to comply. They affirmed that ensuring a method of their preferences was an act of 'being responsible for self'. As one participant put it, 'he has no right to decide.' Another participant also described how she makes all the decisions about contraception and her partner does not interfere nor care. Similarly, one 
participant expressed that despite her partner preferring not to use the condom, for her, taking pills instead was not an option because she did not like the side-effects that came with them.

he always wants me to be on the pill. Yeah. 'Cause - yeah, of course, it feels better, but - no, I don't wanna feel moody and I don't wanna look ugly again with all this pimple

(Participant 11, not married, aged 18-30, no children)

There was also a consideration for sexually transmitted infection (STI) prevention by using condoms among unmarried women.

To me, it is not only about the condom being able to prevent unplanned pregnancy, it is also about it being able to prevent STIs. Although I am willing to believe that my partner is clean, but I think, to me, it is very important [preventing STIs]

(Participant 1, not married, aged 18-30, no children)

Therefore, young unmarried Chinese women often saw requesting condom use as an act of self-protection against unintended pregnancies, STIs and potential sideeffects of other female-initiated methods. In their relationship dynamics, they were highly motivated to use condoms and it was implied that their partners were expected to conform to their preferences.

\section{Theme four: It is not necessary to seek medical advice in choosing contraceptive methods}

When asked if they had ever seen a doctor to discuss contraception or considered seeing one, some participants felt confused by the question as to why a doctor would be needed. For example:

I have not, yet, I never thought about that [seeing a doctor], because I felt that I can resolve this problem myself, but I don't understand, seeing a doctor, do you mean seeing a doctor and doctor give me some advice or something? I probably would not, I would probably just decide on my own

(Participant 14, not married, aged 18-30, no children)

\section{Sub-theme 4a: Did not need to consult a doctor regarding contraceptive methods}

Some women cited cultural and national context differences between their home country and Australia as reasons why they thought seeing a doctor was unnecessary.
They described that people did not have to go to a doctor specifically for asking which contraceptive method to choose. Women's accounts also implied that even for IUD insertions requiring a health professional, doctors's involvement was usually procedural. One woman, who had experienced an IUD insertion in China postnatally described:

\section{no one would consult a doctor about how to avoid pregnancy/birth control, [doctors] normally and only say, have you given birth yet, if you have, let's put the ring in, they all say things like this, then put the ring in. They would not discuss too much, no one would tell you if there is any effect of the ring or if it hurt... In China, the doctor-patient relationship, sometimes it is very tense, and sometimes, some- times there is not much talk, because they fear, fear if they say something and it causes some reaction, then the patient would come to the hospital to dis- pute}

(Participant 22, married, aged 30-45, one child)

Regulations around prescribing contraceptives also added to the contextual differences between the two countries. Participants mentioned that they did not need a prescription for contraceptive pills or devices in China. These could be purchased at a pharmacy. One woman in our study also mentioned that she bought contraceptive pills when she was back in China because it was cheaper there.

\section{Sub-theme 4b: Needing to use contraception is not an illness to be treated}

Also common among our participants was the view that one only needed to see a doctor to treat illnesses or fix something, e.g., when someone is accidentally pregnant and needed an abortion or they were suffering from complications or having gynaecological problems.

I think you only need to see a doctor when you have a problem that you need to fix, like the problem is already there, like falling pregnant accidentally. I don't think I would choose to go and specifically see a doctor and ask how to avoid falling pregnant.... also, I don't know if it is the same in other cultures or countries, but in China, people tend to conceal one's sickness rather than to tell the doctor, sometimes you would have a cold but you would not want to go see a doctor. First, it is the trouble, second, after seeing a doctor, you would feel that your body is in an inferior state, you would have that sort of psychological hint

(Participant 9, not married, 18-30, no children) 
Some women cited that they did not feel the need to consult a doctor because the condom as a contraceptive method was common knowledge and there was no need to consult a doctor. When specifically probed about whether they ever felt any difficulties in choosing contraceptive methods, many participants, especially those who preferred condoms, expressed that it was a straightforward thing to think of using condoms, therefore they had no difficulties.

\section{Sub-theme 4c: Can get contraception related information elsewhere: reliance on Chinese language websites, social networking forums and WeChat groups}

One of the other reasons given by participants for not needing to consult a doctor was that they could easily find information elsewhere. Many participants expressed their preferences for Chinese language online resources, because they were easier to read and comprehend. Zhihu, which is a Chinese equivalent of question-and-answer website Quora, was cited by several participants as a reliable and relatively authentic source for contraception related information. Also among the mentioned Chinese websites were Guoke and DingXiangYuan, which are China-based popular science news and knowledge websites. Apart from those websites, there was a general inclination for hearing other women's real-life experiences with the contraceptives by reading reviews or asking questions on social networking and discussion boards, Weibo (the Chinese equivalent of Twitter) and Wechat groups.

One particular woman, who had chosen a hormonal IUD after it was recommended by her general practitioner, decided to participate in our study to tell her story. She stressed that hormonal IUD was not as bad as some people wrote online. She recounted how she was scared of the side-effects of the hormonal IUD after reading many negative reviews online. However, after giving it a try, she was satisfied with her chosen method.

'I wanted to be in this study, because I did not want it to end up with all the people saying bad things about it [hormonal IUD]. In fact there are people who used and liked it, in fact sometimes people do not bother to say something, because usually there is not a problem, you don't pay attention to it, you are busy with other things. Those who talk about those things all day are those who had unresolved problems, that is why we hear unhappy views everywhere (Participant 4, married, aged 30-45, one child)

\section{Discussion}

This interview-based qualitative study explored Chinese migrant women's perceptions of, preferences for and experiences with choosing a contraception method in Australia. We identified four main themes from our participants' accounts of the contraceptive methods that they knew or used and the processes they took to choose contraceptive methods either in Australia or China. Based on the principles of critical realism, we will now explore how those perceptions and experiences of women are likely to be shaped and generated by personal, cultural and social contexts and mechanisms.

Our findings with respect to women's perceptions and views of contraceptive methods suggest that there is a strong sense of rejection of hormonal contraceptive methods due to fear of side-effect and the profound belief of 'every medicine is part poison'. The most commonly feared side-effect was reduced or absent menses as a result of hormonal contraceptive use. Such finding is in line with earlier studies looking into ethnic Chinese women's beliefs and experiences with contraceptives in other Western countries [29, 30]. The women's responses signalled an underlying belief system related to being a woman, menstruation, fertility, aging and body constitution. Body constitution is a key indicator of a person's physical wellbeing in Traditional Chinese Medicine (TCM) [31], which is deeply rooted in the Chinese view of health and practices [32]. There are nine types of constitutions, including balanced and peaceful (ideal), Qi (vital energy)-deficiency, Yang (positive force)-deficiency, Yin (negative force)-deficiency, Phlegm-dampness, Dampheat, Stagnant Blood, Stagnant Qi (vital energy), and Inherited Special Constitutions [31]. In TCM, when the body's constitution is other than balanced and peaceful, it would mean that there is disharmony within the body which could be identified by associated symptoms) [31]. As for women, an unbalanced constitution could often manifest itself in the form of menstrual disorders, as the classic saying goes 'in women, blood is the ruling aspect, with blood and Qi being interdependent' [33]. Menstruation once-a-month is regarded as a process where old blood is cleansed out of body and new blood begins to generate inside the body [33-35]. Regular, monthly menstruation is seen as a signal of fertility as well as general health and the absence of menses was viewed as the most serious menstrual crisis [33-35]. Therefore, the most prominent menstrual therapy in TCM is based on the notion of 'replenishing and vivifying' female blood by invoking regular menstrual blood loss [33-35]. Such concepts around body constitution and menstruation could potentially helpful to explain why some women in our study were fearful of hormonal contraceptives that might reduce/eliminate the amount of menstrual bleeding. An 
earlier 5-year follow up study on the safety of levonorgestrel-IUD among Chinese patients also found high discontinuation rates among users, mainly due to amenorrhea and irregular bleeding [36]. Another study also found that worry about future fertility was the most common anxiety in relation to IUDs and implants among post-abortion Chinese women [37].

As for IUDs, the historical and societal context of IUD use for parous women in the past and experiences of other family members, friends and themselves made this a non-option for women who had other choices or who are not married or do not have children yet. In China, it was reported that in 2016, IUDs accounted for 53\% of all contraceptive methods that were used by married women of childbearing age [38]. However, there is a trend of decline in the use of IUDs, especially in economically developed cities/provinces [38]. For example, in Beijing, condoms were the main method of birth control in 2016, with a $78.9 \%$ prevalence rate, and the IUD prevalence rate was just under $20 \%$ [38]. Condoms were also found to be the most prevalent contraceptive method (61.4\%) among unmarried women in China, followed by rhythm (19.8\%) and withdrawal (25.4\%) methods [39]. There are no statistics of the prevalence of contraceptive method use among Chinese women living in Australia. However, accounts of women who were interviewed in this study suggest that for them, the IUD is not a desirable option that they would consider at first. There was also concern about a foreign object being placed in their body which invoked fears about both the procedure itself and the potential complications. Such concerns, however, are not unique to Chinese women living in Australia. Worries about infection, perforation, expulsion as well as troublesome bleeding have been identified by several studies amongst different population groups [40-43].

Given that hormonal contraceptives and non-hormonal IUDs are generally not preferred by women, at least initially, we found that women usually intend/prefer to use condoms with or without withdrawal and fertilityawarenss based methods. Such intentions can subject to influences from multiple factors, including partner preferences and provider recommendations [44]. In our study, partner preferences were found to be more influential among married women than unmarried and noncohabiting women. There was a sense of appreciation among married women that their choice of the condom as a contraceptive method was granted and fulfilled by their husbands. A similar study from mainland China also revealed how women often expressed that their husband made the 'caring' decision to use condoms as a contraceptive method [45]. A study conducted by Miller and Pasta found that, among married couples who were currently using condoms or diaphragms, husbands were likely to conform to their wife's contraceptive method desires rather than their own [46]. On the other hand, when women were not confident in their husbands' use of condoms, they are more likely to intend to change methods [46]. Also, when method choice was femalecontrolled, women tended to have more influence on the decisions than those required male cooperation $[46,47]$. This was also the case for some women in our study who chose IUDs without involving their husband in the decision-making process. By contrast, for unmarried women, we found that they placed little to no weight on the preferences of their partners.

We found that for both the married and unmarried Chinese migrant women, influence from providers was mostly absent from their decision-making processes. Our findings revealed an underlying belief that one only need to see a doctor to treat illness, and that the need for contraception was not illness. A prior study conducted among Chinese immigrants also found that Chinese immigrants believed the doctor's role was to prescribe medications [48]. They tended to seek medical advice only when their conditions were perceived as serious [48]. It was found that for perceived minor illness, Chinese migrants preferred self-management [48, 49]. In Australia, on study found that around every six out of 100 general practice consultations are contraceptive management related [50]. Apart from the prescription of medications, general counselling and education were one of the most common types of non-pharmacological management of contraception problems [50]. Unsurprisingly, it also reported that women who speak a language other than English were less likely to have contraceptive management related encounters with general practitioners compared to English-speaking only women [50].

Our study results show that women often acquired their information about contraception on Chinese language websites and platforms, because of the ease of reading. Majority of the participants mentioned or were aware of the Australian family planning specific websites, pointing to system and language barriers as well as inequalities in access to health information and services. We also found that women preferred experiential information on contraceptive methods by learning about reallife experiences of other women. This finding is similar to other studies where women expressed seeking experiential information on contraceptive methods $[51,52]$. In most cases, healthcare providers or local Australian contraception related evidence-based resources were usually not the first point of contact for information and advice. This finding should have important policy and practice implications for delivering reproductive health services to Chinese migrant women in Australia, specifically in terms of contraceptive services. 


\section{Implications for policy and practice}

This study has several implications for policy and practice. It is undoubtedly challenging to deliver the current best practices in contraception counselling, such as patient centred care and shared decision-making [53], to Chinese migrant women who are making their contraception decisions without involving healthcare providers. However, when women do present to healthcare providers with contraception related problems, in line with best practices and on the basis of respecting women's reproductive autonomy and rights, proactively eliciting and acknowledging women's preferences and concerns around contraceptive methods is likely help women make informed decisions. For example, it may be necessary to provide explanation to how contraceptives work, especially hormonal ones, and how they impact menstrual bleeding patterns and subsequent fertility, as these were among the major concerns of women. Where necessary, explaining the differences between current day copper and hormonal IUDs and those IUDs used in the past, notably SSRs, is likely to help addressing women's concerns around IUDs. It might be also imperative for healthcare providers to explain the procedures involved in IUD insertions, especially around pain and potential complications. In all cases, providing evidence-based information on the side-effects and their probabilities is likely to ensure a method choice that is concordant with women's preferences and based on evidence-based information.

Most importantly, to better cater to women's information, communication and support needs in terms of contraceptive method-choice decision, interventions may need to expand their focus from the counselling domain to broader health literacy, health education and promotion domains. Such interventions can serve to provide women equal access to evidence-based and Australiancountry specific contraceptive related resources. Interventional strategies could include developing culturally and linguistically sensitive contraception related educational materials, decision support tools and interactive workshops/seminars and delivering them through channels that are easily accessed by Chinese migrant women. One of the implications from our study is also the importance of integrating user testimonies into the health education and decision support materials. Also important is improving migrant women's awareness of healthcare providers' role in providing contraceptive related counselling and related services. It is often reported that immigrants' health seeking behaviours are influenced by their prior experiences of accessing healthcare in in their country of origin [12, 54]. Therefore, integrating messages, such as availability of counselling and other services, to health education materials, welcome to country/university packs is likely to help improve health system awareness.

\section{Limitations}

Despite our efforts to recruit women who are seeking contraception services at family planning clinics, we were only able to recruit one participant from such venues due to low representation at such clinical settings. Therefore, the views and perceptions expressed by women in our study may not be representative of those women who actively sought medical help for managing their contraceptive needs. We also only recruited women who had been living in Australia for no more than 10 years to minimise the impact of acculturation and to target those who are most likely to be culturally and linguistically distinct. Also, due to voluntary nature of recruitment, those women who had decided to participate in our study might be more open to discussing sexual and reproductive matters and more confident with their current chosen contraceptive methods than those that who did not participate. Therefore, our study results should be interepreted in light of the participants' characteristics (Table 1).

\section{Conclusion}

Our findings suggest that Chinese migrant women's perceptions and experiences of contraceptive methods are influenced by complex personal, cultural, societal and inter-relational factors. The findings are likely to be useful in increasing healthcare professionals' and policy makers' understanding of Chinese women's contraceptive method preferences, beliefs and behaviours and improving responsiveness/sensitivity of health services and interventions to cater to women's decision-making needs.

\section{Abbreviations}

IUD: Intrauterine device; SSR: Stainless steel ring; STI: Sexually transmitted infection; TCM: Traditional Chinese Medicine.

\section{Supplementary Information}

The online version contains supplementary material available at https://doi. org/10.1186/s12905-021-01226-3.

Additional file 1: Interview script and topic guide.

\section{Acknowledgements}

We sincerely thank the women who had participated in our study and generously shared their time, experiences and views.

Authors' contributions

$H D, L T, M L$ and DB developed the study concept. HD, LT, ML, DB, MT and CB contributed to developing research questions, sampling and recruitment 
methods and overall design of the study. HD carried out the data collection. $H D, L T, M L, D B, R T$ and MT contributed to data analysis and interpretation of data. HD drafted the initial manuscript. LT, ML, DB, RT, MT and CB read and critically reviewed the manuscript. All authors have read and approved the manuscript.

\section{Funding}

HD's doctorate study is supported by Australian National Health and Medical Research Council (NHMRC)/Centres of Research Excellence project: Testing, Translation and Uptake of Evidence in General Practice: A systems approach to rapid translation. The funding agreements ensured the authors' independence in designing the study, interpreting the data, writing, and publishing the report.

\section{Availability of data and materials}

The data generated during the current study will be available from the corresponding author on reasonable request and in accordance with the consent and ethical approval.

\section{Ethical approval and consent to participate}

Ethical approvals were obtained from the University of Sydney human research ethics committee [ref: 2018/159] and Family Planning NSW Project Ethical Risk Team (PERT) [ref: PERT 25]. All participants read the participant information statement and consent form. Written consent forms were obtained from 20 participants and verbal consent was obtained from two participants. Verbal consent was obtained when interviews were conducted over the phone and participants were not able to return a written consent form prior to the interviews. Verbal consent was recorded in a Verbal Consent Log which was approved by the University of Sydney human research ethics committee.

\section{Consent for publication}

Not applicable.

\section{Competing interests}

DB has been supported to attend educational events by Bayer Healthcare and MSD, both are manufacturers of contraceptives, and have attended advisory committees for these companies as part of her role at Family Planning New South Wales. All other authors declare that they have no conflict of interest.

\section{Author details}

${ }^{1}$ School of Public Health, The University of Sydney, Room 125, Edward Ford Building, Sydney, NSW 2006, Australia. ${ }^{2}$ Ask, Share, Know: Rapid Evidence for General Practice Decision (ASK-GP), Centre for Research Excellence, The University of Sydney, Sydney, NSW 2006, Australia. ${ }^{3}$ Family Planning NSW, Sydney, NSW 2131, Australia. ${ }^{4}$ Discipline of Obstetrics, Gynaecology and Neonatology, The University of Sydney, Sydney, NSW 2006, Australia. ${ }^{5}$ Primary and Integrated Care Unit, South Western Sydney Local Health District, Liverpool, NSW 2170, Australia. ${ }^{6}$ School of Population Health, Faculty of Medicine, UNSW, Sydney, NSW 2052, Australia.

Received: 3 September 2019 Accepted: 16 February 2021

Published online: 08 March 2021

\section{References}

1. Australian Bureau of Statistics. Cultural diversity: who we are now. ABS, Canberra; 2017. https://www.abs.gov.au/ausstats/abs@.nsf/Latestprod ucts/2024.0Main\%20Features22016? opendocument\&tabname=Summa ry\&prodno=2024.0\&issue $=2016 \&$ num $=\& v i e w=$. Accessed 15 Sept 2019.

2. Australian Bureau of Statistics. Over 28 percent of Australians born overseas. ABS, Canberra; 2017. https://www.abs.gov.au/ausstats/abs@.nsf/ lookup/3412.0Media\%20Release12015-16. Accessed 19 Sept 2019.

3. Australian Bureau of Statistics. 2016 census quickstats country of birth. ABS, Canberra; 2019. https://quickstats.censusdata.abs.gov.au/census_ services/getproduct/census/2016/quickstat/036. Accessed 12 Sept 2019.

4. Australian Bureau of Statistics. ABS Chinese new year insights. ABS, Canberra; 2019. https://www.abs.gov.au/AUSSTATS/abs@.nsf/mediarelea sesbytitle/D8CAE4F74B82D446CA258235000F2BDE?OpenDocument. Accessed 12 Sept 2019.
5. Starrs AM, Ezeh AC, Barker G, Basu A, Bertrand JT, Blum R, et al. Accelerate progress - sexual and reproductive health and rights for all: report of the Guttmacher-Lancet Commission. Lancet. 2018;391(10140):2642-92. https://doi.org/10.1016/s0140-6736(18)30293-9PMID-29753597.

6. World Health Organisation Department of Reproductive Health and Research (WHO/RHR), Johns Hopkins Bloomberg School of Public Health/ Center for Communication Programs (CCP). Family planning: a global handbook for providers. 2018. Baltimore and Geneva: CCP and WHO; 2018.

7. Bateson D, Harvey C, McNamee K. Contraception: an Australian clinical practice handbook. Ashfield: Family Planning NSW, Family Planning VIC, True Relationship and Reproductive Health; 2016.

8. Richters J, Fitzadam S, Yeung A, Caruana T, Rissel C, Simpson JM, et al. Contraceptive practices among women: the second Australian study of health and relationships. Contraception. 2016;94(5):548-55. https://doi. org/10.1016/j.contraception.2016.06.016PMID-27373543.

9. Family Planning NSW. Reproductive and sexual health in Australia. Ashfield, Sydney: FPNSW; 2013.

10. Freilich K, Holton S, Rowe H, Kirkman M, Jordan L, McNamee K, et al. Sociodemographic characteristics associated with the use of effective and less effective contraceptive methods: findings from the Understanding Fertility Management in Contemporary Australia survey. Eur J Contracept Reprod Health Care. 2017;22(3):212-21.

11. Hach M. Common Threads: the sexual and reproductive health experiences of immigrant and refugee women in Australia. MCWH; 2012.

12. Ussher J, Perz J, Metusela C, Hawkey A, Morrow M, Narchal R, et al. Sexual and reproductive health of migrant and refugee women. Penrith, Sydney: University of Western Sydney; 2017.

13. Burchard A, Laurence C, Stocks N. Female international students and sexual health - a qualitative study into knowledge, beliefs and attitudes. Aust Fam Phys. 2011:40(10):817-20.

14. Baek Y, Akbar H, Baguley G, eds. Relationships and sexual health promotion project for QUT international students. In: 23rd ISANA international education association conference 2012 4-7 December; Aucland, New Zealand. Hobart: ISANA International Education Association Inc; 2012.

15. Poljski C, Quiazon R, Tran C. Ensuring rights: improving access to sexual and reproductive health services for female international students in Australia. J Int Stud. 2014;4(2):150-63.

16. Dehlendorf C, Grumbach K, Schmittdiel JA, Steinauer J. Shared decision making in contraceptive counseling. Contraception. 2017;95(5):452-5. https://doi.org/10.1016/j.contraception.2016.12.010PMID-28069491.

17. Bhaskar R. A realist theory of science. 1st ed. London: Routlege; 2008.

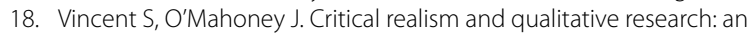
introductory overview; 2018.

19. Ayres L. Semi-structured interview. In: Given L, editor. The SAGE encyclopedia of qualitative research methods. Thousand Oaks: SAGE Publications, Inc.; 2008. p. 811-3.

20. Jacobsen MJ, O'Connor AM, Stacey D. Decisional needs assessment in populations: a workbook for assessing patients' and practitioners' decision making needs. Ottowa: University of Ottawa; 2013.

21. Nes FV, Abma T, Jonsson H, Deeg D. Language differences in qualitative research: is meaning lost in translation? Eur J Ageing. 2010;7(4):313-6. https://doi.org/10.1007/s10433-010-0168-y.

22. Braun V, Clarke V. Using thematic analysis in psychology. Qual Res Psychol. 2006;3(2):77-101.

23. QRS International Pty Ltd. Nvivo qualitative analysis software; 2018.

24. Nowell LS, Norris JM, White DE, Moules NJ. Thematic analysis: striving to meet the trustworthiness criteria. Int I Qual Methods. 2017;16(1):1609406917733847.

25. Spall S. Peer debriefing in qualitative research: emerging operational models. Qual Inquiry. 1998;4(2):280-92.

26. Fletcher AJ. Applying critical realism in qualitative research: methodology meets method. Int J Soc Res Method. 2016. https://doi. org/10.1080/13645579.2016.1144401.

27. Kaufman J. The cost of IUD failure in China. Stud Fam Plann. 1993;24(3):194-6.

28. China changes from the stainless steel ring to modern IUDs. Prog Hum Reproduction Res. 1993(27):7.

29. Verran A, Evans S, Lin DJ, Griffiths F. The experiences and perceptions of family planning of female Chinese asylum seekers living in the UK. J Fam Plann Reprod Health Care. 2015;41(2):122-7. 
30. Wiebe ER, Janssen PA, Henderson A, Fung I. Ethnic Chinese women's perceptions about condoms, withdrawal and rhythm methods of birth control. Contraception. 2004;69(6):493-6. https://doi.org/10.1016/j.contr aception.2004.01.006PMID-15157795.

31. Wang J, Li Y, Ni C, Zhang H, Li L, Wang Q. Cognition research and constitutional classification in Chinese medicine. Am J Chin Med. 2011;39(04):651-60. https://doi.org/10.1142/s0192415×11009093PM D-21721146.

32. Chung VC, Ma PH, Lau CH, Wong SY, Yeoh EK, Griffiths SM. Views on traditional Chinese medicine amongst Chinese population: a systematic review of qualitative and quantitative studies. Health Expect. 2014;17(5):622-36.

33. Furth C. Blood, body and gender: medical images of the female condition in China 1600-1850. Chin Sci. 1986;7:43-66.

34. Furth C, Shu-yueh CE. Chinese medicine and the anthropology of menstruation in contemporary Taiwan. Med Anthropol Q. 1992;6(1):27-48. https://doi.org/10.1525/maq.1992.6.1.02a00030.

35. Chu CMY. Menstrual beliefs and practices of Chinese women. J Folklore Inst. 1980;17(1):38-55.

36. Zhang $\sqcup$, Weng $L$ J. Safety study of LNG-IUS after 5 years of clinical trial. Chin J Obstet Gynecol. 2001;36:675-7.

37. Luo Z, Gao L, Anguzu R, Zhao J. Long-acting reversible contraceptive use in the post-abortion period among women seeking abortion in mainland China: intentions and barriers. Reprod Health. 2018;15(1):85. https://doi. org/10.1186/s12978-018-0543-2PMID-29793501.

38. Zou Y, Liu H, Wang H. Evolution of contraception mix in China, 20102016. Popul Res. 2018:42(5):3-16.

39. Wang M-Y, Zhang W-H, Mu Y, Temmerman M, Li J-K, Zheng A. Contraceptive practices among unmarried women in China, 1982-2017: systematic review and meta-analysis. Eur J Contracept Reprod Health Care. 2019. https://doi.org/10.1080/13625187.2018.1555641.

40. Black K, Lotke P, Buhling KJ, Zite NB, group obotlcfNwTRiA. A review of barriers and myths preventing the more widespread use of intrauterine contraception in nulliparous women. Eur J Contracept Reproduct Health Care. 2012;17(5):340-8. https://doi.org/10.3109/13625187.2012.700744.

41. Twesigye R, Buyungo P, Kaula H, Buwembo D. Ugandan women's view of the IUD: generally favorable but many have misperceptions about health risks. Glob Health Sci Pract. 2016;4(Supplement 2):S73-82.

42. Michie L, Cameron ST, Glasier A, Wellings K, Loudon J. Myths and misconceptions about intrauterine contraception among women seeking termination of pregnancy. J Fam Plann Reprod Health Care. 2014;40(1):36-40.

43. Katz KR, Johnson LM, Janowitz B, Carranza JM. Reasons for the low level of IUD use in El Salvador. Int Fam Plan Perspect. 2002;28:26-31.

44. Miller WB. Reproductive decisions: how we make them and how they make us. Adv Popul Psychosoc Perspect. 1994;2:1.
45. Che Y, Dusabe-Richards E, Wu S, Jiang Y, Dong X, Li J, et al. A qualitative exploration of perceptions and experiences of contraceptive use, abortion and post-abortion family planning services (PAFP) in three provinces in China. BMC Women's Health. 2017;17(1):113. https://doi.org/10.1186/ s12905-017-0458-zPMID-29157259.

46. Miller WB, Pasta DJ. The relative influence of husbands and wives on the choice and use of oral contraception, a diaphragm, and condoms 1. J Appl Soc Psychol. 1996;26(19):1749-74.

47. Irala JD, Osorio A, Carlos S, Burgo CLD. Choice of birth control methods among European women and the role of partners and providers. Contraception. 2011;84(6):558-64. https://doi.org/10.1016/j.contracept ion.2011.04.004.

48. Liu Z, Beaver K, Speed S. Chinese Elders' views on their interactions in general practice: a Grounded Theory study. Ethnic Health. 2014;20(2):129-44. https://doi.org/10.1080/13557858.2014.890176PMID $-24559295$.

49. Tam WJ, Goh WL, Chua J, Legido-Quigley H. 健康是本钱-Health is my capital: a qualitative study of access to healthcare by Chinese migrants in Singapore. Int J Equity Health. 2017;16(1):102.

50. Mazza D, Harrison C, Taft A, Brijnath B, Britt H, Hobbs M, et al. Current contraceptive management in Australian general practice: an analysis of BEACH data. Med J Aust. 2012;197(2):110-4. https://doi.org/10.5694/ mja11.11599PMID-22794058.

51. Marshall C, Kandahari N, Raine-Bennett T. Exploring young women's decisional needs for contraceptive method choice: a qualitative study. Contraception. 2018;97(3):243-8. https://doi.org/10.1016/j.contracept ion.2017.10.004PMID-29038070.

52. Asker C, Stokes-Lampard H, Beavan J, Wilson S. What is it about intrauterine devices that women find unacceptable? Factors that make women non-users: a qualitative study. J Fam Plan Reprod Health. 2006;32(2):8994. https://doi.org/10.1783/147118906776276170PMID-16824298.

53. Dehlendorf C, Krajewski C, Borrero S. Contraceptive counseling. Clin Obstet Gynecol. 2014;57(4):659-73. https://doi.org/10.1097/grf.00000 00000000059PMID-25264697.

54. Mengesha ZB, Perz J, Dune T, Ussher J. Refugee and migrant women's engagement with sexual and reproductive health care in Australia: a socio-ecological analysis of health care professional perspectives. PLoS ONE. 2017;12(7):e0181421. https://doi.org/10.1371/journal.pone.0181421.

\section{Publisher's Note}

Springer Nature remains neutral with regard to jurisdictional claims in published maps and institutional affiliations.
Ready to submit your research? Choose BMC and benefit from:

- fast, convenient online submission

- thorough peer review by experienced researchers in your field

- rapid publication on acceptance

- support for research data, including large and complex data types

- gold Open Access which fosters wider collaboration and increased citations

- maximum visibility for your research: over $100 \mathrm{M}$ website views per year

At BMC, research is always in progress.

Learn more biomedcentral.com/submissions 